\title{
A study of patients' quality of life more than 5 years after trauma: a prospective follow-up
}

\author{
Fanny Vardon-Bounes ${ }^{1,2^{*}} \mathbb{0}$, Romain Gracia ${ }^{1}$, Timothée Abaziou' ${ }^{1}$, Laure Crognier ${ }^{1}$, Thierry Seguin ${ }^{1}$, \\ François Labaste ${ }^{1}$, Thomas Geeraerts ${ }^{1}$, Bernard Georges ${ }^{1}$, Jean-Marie Conil ${ }^{1}$ and Vincent Minville ${ }^{1,2}$
}

\begin{abstract}
Background: The long-term fate of severely injured patients in terms of their quality of life is not well known. Our aim was to assess the quality of life of patients who have suffered moderate to severe trauma and to identify primary factors of long-term quality of life impairment.
\end{abstract}

Methods: A prospective monocentric study conducted on a number of patients who were victims of moderate to severe injuries during the year 2012. Patients were selected based on an Injury Severity Score (ISS) more than or equal to 9. Quality of life was assessed by the MOS SF-36 and NHP scores as a primary evaluation criterion. The secondary evaluation criteria were the determination of the socio-economic impact on quality of life and the identification of factors associated with disability.

Results: Two hundred and eight patients were contacted by e-mail or telephone. Fifty-five patients participated in this study (with a participation level of $26.4 \%$ ), including $78.2 \%$ men, with a median age of 46 . Significant alterations in quality of life were observed with the NHP and MOS SF-36 scale, including physical and psychological components. This resulted in a major socio-economic impact as $26 \%$ of the patients could not resume their professional activities $(n=10), 20 \%$ required retraining in other lines of work, and $36.4 \%$ had a disability status. The study showed that scores $\leq 85$ on the physical functioning variable of the MOS SF 36 scale was associated with disability.

Conclusion: More than five years after a moderate to severe injury, patients' quality of life was significantly impacted, resulting in significant socio-economic consequences. Disability secondary to major trauma seems to be associated with a score $\leq 85$ on the physical functioning dimension of the MOS SF-36 scale. This study raises the question of whether or not early rehabilitation programs should be implemented in order to limit the long-term impact of major trauma.

Keywords: Quality of life, Trauma, NHP, MOS-SF36, Disability, Rehabilitation

\section{Background}

Trauma is a frequent reason for admission to intensive care units (ICU) [1]. A recent study revealed a 30-day mortality of $5.9 \%$ in a retrospective French cohort of

*Correspondence: bounes.f@chu-toulouse.fr

${ }^{1}$ Anesthesiology and Critical Care Unit, Toulouse University Hospital, 1 av du Pr Jean Poulhès, 31059 Toulouse, France

Full list of author information is available at the end of the article
144,058 trauma patients in which age and injury severity were the stronger predictors for mortality [2]. In the United States, severe trauma is the cause of 2 million hospitalizations and results in over 150,000 deaths. There is a major socio-economic impact, with medical fees for severely injured patients resulting in an estimated annual cost of 16 million dollars, while costs related to secondary disabilities from these traumas are estimated at 150 billion dollars annually [3]. original author(s) and the source, provide a link to the Creative Commons licence, and indicate if changes were made. The images or other third party material in this article are included in the article's Creative Commons licence, unless indicated otherwise in a credit line to the material. If material is not included in the article's Creative Commons licence and your intended use is not permitted by statutory regulation or exceeds the permitted use, you will need to obtain permission directly from the copyright holder. To view a copy of this licence, visit http://creativecommons.org/licenses/by/4.0/. The Creative Commons Public Domain Dedication waiver (http://creativeco mmons.org/publicdomain/zero/1.0/) applies to the data made available in this article, unless otherwise stated in a credit line to the data. 
Numerous studies conducted in patients with Acute Respiratory Distress Syndrome (ARDS) and/or sepsis [48], have helped to highlight the development of varying but often very frequent cases of functional and neuropsychological disorders after hospitalization in the ICU. The British health community defines this disorder as "PICS" for "Post Intensive Care Syndrome". In an extensive research review including 19 articles, Wolters et al. [9] highlight the fact that 4 to $62 \%$ of patients present with cognitive impairments after care in the ICU.

However, in Europe few studies have shown interest in the outcome of patients who have suffered moderate to severe traumas [10].

Braithwaite et al. found that half of the patients who suffered from a major trauma developed moderate to severe disabilities [11]. Sluys et al. found significant physical and psychological impairments in respectively $68 \%$ and $41 \%$ of the patients [12]. The Von Rüden et al. study showed that $85 \%$ of the patients had an impaired capacity to work, and $62 \%$ lived with chronic pain. In addition to these results, $48 \%$ of the patients showed signs of clinical depression and $41 \%$ were victims of post-traumatic stress after experiencing trauma [10].

To our knowledge, no studies concerning the long-term outcome of patients with moderate to severe trauma have been conducted in France.

The main objective of our study was to assess the longterm outcome and quality of life in moderate to severe trauma patients managed in a Level 1 trauma center, more than five years after their injury. Secondly, we investigated the predictive factors for long-term alterations in their quality of life, as well as the socio-economic repercussions.

\section{Methods}

\section{Study population}

The study was conducted in the Level 1 trauma center at Toulouse University Hospital in 2017.

All patients aged $>16$, admitted in Intensive Care Unit, who have been discharged alive after a moderate or severe trauma five years earlier were screened in the study. An ISS (Injury Severity Score) more than or equal to 9 qualified the trauma as moderate to severe. The exclusion criteria were patients dead at day 30, minors, and beneficiaries of judicial forms of protection.

The Toulouse University Hospital ethics and research committee approved this study (project number 08-0916). Informed consent was obtained through forms from all the participants in the study.

\section{Proceedings}

All the medical and administrative data gathered on the potentially eligible patients were analyzed retrospectively.
All patients known to have survived major trauma were then contacted by mail, and then by phone.

Initially, all necessary documents were sent by mail, including various quality of life surveys, a written information form, an informed consent form and a stamped envelope for the main investigator, in order to collect all duly completed informed consent forms and surveys. In the second stage, once the initial documents were mailed to patients, a telephone call was made to gather additional information, and if the patients agreed, a complete interview was conducted to allow them to answer questions on the phone.

\section{Selection criteria}

The primary endpoint of the study was the assessment of quality of life 5 years after the trauma. Therefore, two standardized scientifically approved scales were used: The Medical Outcome Study Short Form-36 (MOSSF-36) and the Nottingham Health Profile (NHP). MOS SF-36 is a multidimensional, generic scale that assesses health status independently of causal pathology, sex, age, and treatment. This survey, made up of 36 different fields of inquiry, evaluates eight dimensions of health: physical functioning, limitations due to physical conditions, physical pain, mental health limitations due to mental status, social functioning, vitality and general health. An average physical score and an average emotional score can be calculated from these 8 dimensions according to an existing algorithm. The Nottingham Health Profile is a scale that was published in Britain at the end of the 1970s. The French version was edited and validated by Bucquet et al. [13] in 1990. Like the MOS SF-36, age and sex do not influence the value of the score. This scale is comprised of 38 items that assess 6 dimensions: mobility, social isolation, pain, emotional reactions, energy and sleeping habits. Scores rank from 0 to $100 \%$.

In addition, another survey developed specifically for this study was provided to patients to subjectively describe their rehabilitation, the impact of their trauma on their professional lives, leisure, and disability status according to criteria from the French Health Insurance Agency. Factors associated with disability were the secondary endpoints.

\section{Acquired data}

Data were retrieved from the Orbis ${ }^{\circledR}$ software (Agfa Healthcare, Bordeaux, France) which gathers all hospitalized patients' medical and administrative information at the University Hospital Center.

The following data were collected:

- Demographic data: age, gender, nature of the initial injury, severity scores (SAPS II (New Simplified 
Acute Physiology Score II) and ISS (Injury Severity Score)), data relating to treatment plans followed (transfusion, surgical care, embolization, mechanical ventilation), the main biological parameters and the patient outcome (length of stay in intensive care units and length of hospitalization).

- Previous habits: professional career, driving, regular leisure activities.

- Follow-up information after moderate to severe trauma: number of repeat surgical procedures, number of specialized consultations, evaluation of rehabilitation (length of care, quality of rehabilitation, patient's wish to be under the care of a trauma specialist such as an anesthesiologist).

- Aspects of post-trauma life: resumption of professional activity (work adjustments, partial or full-time job, necessity of professional retraining), the resumption of driving and leisure activities.

- Medical and economic factors: category of invalidity, receipt of disability pension, the average disability payment, employment of a care provider.

\section{Statistical analysis}

- Characteristics of patients were described in terms of averages, minimum, maximum and median, first and third (25-75P) quartile or percentages according to the type of variables.

- For the MOS SF-36, the percentage was set at 100 for the maximal score (e.g. favorable) and 0 for the minimal score (e.g. unfavorable) and vice versa for the NHP score (minimal score 0/100 e.g. favorable, maximal score 100/100 e.g. unfavorable).

- The percentage of patients presenting with a severely altered quality of life was noted. For every dimension of the MOS SF-36, the minimal threshold that defined a severely altered quality of life was calculated from data observed in the French general population (source: INSEE (French Institute of Statistics and Economic Studies) study of health and medical care conducted in 2002-2003). The calculation of statistical significance was not possible due to the difference in the number of patients between the groups and the comparison is given for information purposes only.

The ROC (Receiver Operating Characteristics) curves and their areas under the curve were used to identify the discriminating value for the occurrence of disability. The choice of the most discriminating thresholds was achieved according to Youden's index. After this univariate analysis that allows the individualization of covariates (continuous and nominal) associated with the occurrence of a disability, a multidimensional analysis facilitated the evaluation of different covariates and the disability variable by Risk-Ratio measurement. Results with an alpha $p<0.05$ were considered statistically significant. Statistical analyses were performed using MedCalc ${ }^{\circledR}$ software (Ostend, Belgium).

\section{Results}

Of the 255 patients initially screened in the study, 208 were contacted (Flow chart in Fig. 1). Finally, 55 patients responded to the questionnaire and were included in the final analysis. Demographics and surgical data are shown in Table 1. There was no statistical difference between the responsive and non-responsive population.

\section{Medical follow-up and rehabilitation data}

Following hospital care, 40 patients (74.1\%) benefited from rehabilitation and 25 patients (46.3\%) admitted regretting not having been followed by a trauma specialist such as an anesthesiologist and intensive care provider.

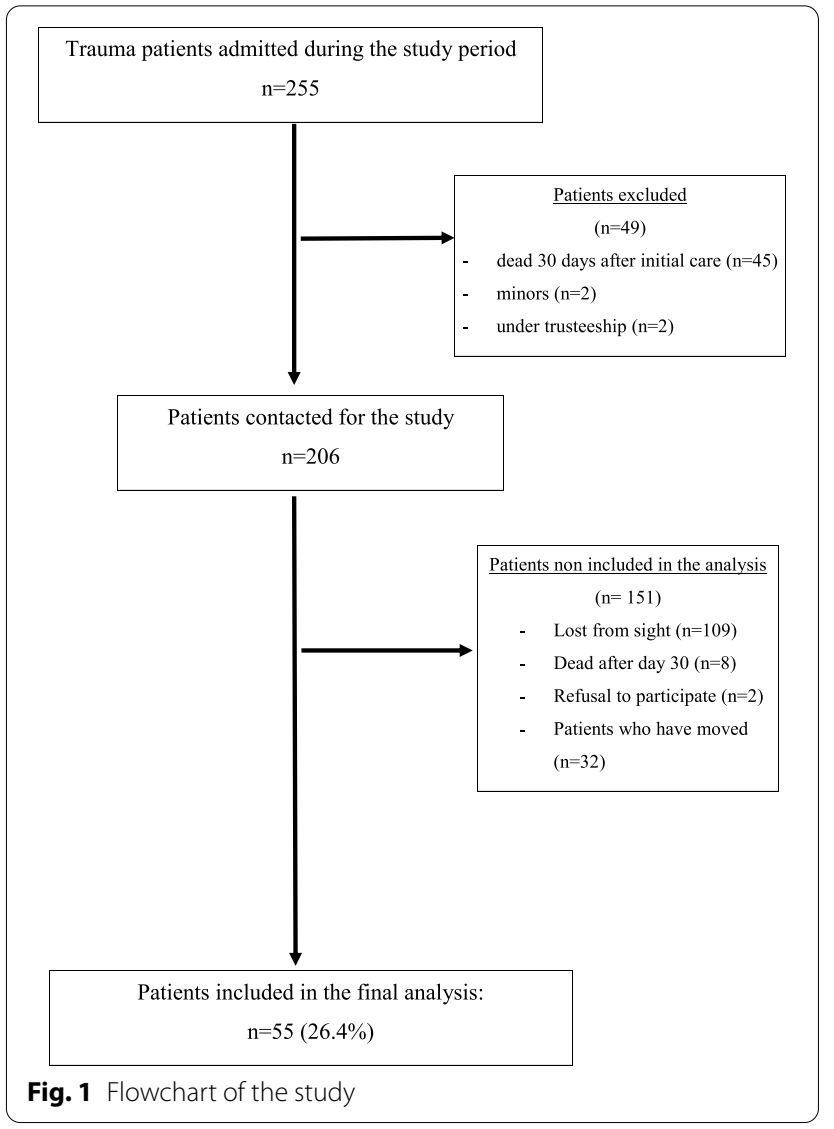


Table 1 Summary of clinical and biological data of the population studied

\begin{tabular}{|c|c|c|c|}
\hline & $\begin{array}{l}\text { Non-responsive population } \\
(n=153)\end{array}$ & Participating population $(n=55)$ & $p$ value \\
\hline \multicolumn{4}{|l|}{ Epidemiological data } \\
\hline Age (years) & 36 [16-88] & $46[17-76]$ & 0.087 \\
\hline SAPS ॥ & $27[6-65]$ & 26 [7-66] & 0.93 \\
\hline ISS & $18[9-41]$ & $18[9-41]$ & 0.42 \\
\hline Gender ratio (Male/female) & $114(74.5 \%) / 39(25.5 \%)$ & $43(78.2 \%) / 12(21.8 \%)$ & 0.59 \\
\hline \multicolumn{4}{|l|}{ Biological data } \\
\hline $\mathrm{pH}$ & 7.5 [7.02-7.99] & $7.35[7.19-7.5]$ & 0.36 \\
\hline Serum lactate $(\mathrm{mmol} / \mathrm{l})$ & $1.9[0.55-12.9]$ & 1.8 [0.4-9.85] & 0.99 \\
\hline Hemoglobin (g/dl) & $12.1[4.5-16.89]$ & $11.6[7.5-16.8]$ & 0.81 \\
\hline \multicolumn{4}{|l|}{ Injury data (n, \%) } \\
\hline Thorax & $111(72.5 \%)$ & $38(69.1 \%)$ & 0.63 \\
\hline Skull & $71(46.4 \%)$ & $31(56.4 \%)$ & 0.21 \\
\hline Limbs & $78(51 \%)$ & $29(52.7 \%)$ & 0.83 \\
\hline Abdomen & $46(30.1 \%)$ & $22(40 \%)$ & 0.18 \\
\hline Spine & $43(28.1 \%)$ & 17 (30.9\%) & 0.70 \\
\hline Pelvis & $41(26.8 \%)$ & $15(27.3 \%)$ & 0.95 \\
\hline Face & $41(26.8 \%)$ & $12(21.8 \%)$ & 0.47 \\
\hline \multicolumn{4}{|l|}{ Therapeutics } \\
\hline Transfusion & $93(61.2 \%)$ & $36(66.7 \%)$ & 0.48 \\
\hline Emergency surgery & $70(47.3 \%)$ & $29(52.7 \%)$ & 0.49 \\
\hline Length of mechanical ventilation (days) & $1[0-52]$ & $1[0-43]$ & 0.33 \\
\hline Length of hospitalization in the ICU (days) & 12 [1-93] & $13[3-63]$ & 0.96 \\
\hline Length of overall hospitalization (days) & $25[2-123]$ & $25[3-108]$ & 0.57 \\
\hline
\end{tabular}

Results expressed in median and extreme values as well as numeric values and averages (\%). SAPS II: Simplified Acute Physiology Score II, ISS: Injury Severity Score

Concerning medical follow-up, the median number of repeat surgical procedures and consultations were respectively $2[0-9]$ and $6[0-31]$.

\section{Social and economic data}

Twenty-six percent of the patients $(n=10)$ did not return to work after their accident. Resumption of full-time activity was permitted in $68 \%$ of the cases. Almost one out of five patients had to be re-trained in a different field of work, and $16.7 \%(n=6)$ had to benefit from an adaptation of their workstation.

Similar to the impact on professional aspects of life, $39.5 \%$ of the patients $(n=17)$ reported having resumed their leisure activities on a regular basis (versus $70 \%$ prior to the accident). Driving was resumed in $94.5 \%$ of the cases $(\mathrm{n}=52)$.

Finally, $36.4 \% \quad(\mathrm{n}=20)$ of the responders were assumed to have a disability status according to criteria by the French Health Insurance Agency. The median rate of disability was $25 \%$.

\section{Quality of life}

The assessment of quality of life data is shown in Table 2 and was explored by the 2 scales mentioned above.

After evaluation with the Nottingham Health Profile scale, the dimensions associated with significant impaired quality of life, therefore those most affected by trauma, were "energy" with $27.8 \%(n=15)$ of the population admitting loss of energy and "pain" (12.7\% of patients $(\mathrm{n}=7)$ admitting major pain), respectively average values of $40.8 \pm 41.6$ and $31.3 \pm 36.8(0 / 100$ corresponding to the best score and 100/100 corresponding to the worst score).

The least altered dimensions were "social isolation" (69.1\% with minimal score stating that patients did not feel isolated), "sleep" (49.1\% of minimal score) and "emotional reaction" (47.3\% of maximal score) (Table 2).

With regard to the MOS SF-36 scale, the most unfavorable scores were related to the items "limitations due to emotional problem" and "limitations due to physical health" with respectively $30.9 \%$ and $29.1 \%$ of patients with minimal score. 
Table 2 Quality of life of the trauma group

\begin{tabular}{|c|c|c|c|}
\hline & Average \pm SD & $\begin{array}{l}\text { Patients with minimal score/item } \\
\text { (favorable) }\end{array}$ & $\begin{array}{l}\text { Patients with maximal } \\
\text { score/item (unfavorable) }\end{array}$ \\
\hline \multicolumn{4}{|l|}{ NHP } \\
\hline Pain & $31.3 \pm 36.8$ & $22(40.0 \%)$ & $7(12.7 \%)$ \\
\hline Energy & $40.8 \pm 41.6$ & $21(38.9 \%)$ & $15(27.8 \%)$ \\
\hline Social isolation & $16.5 \pm 30.9$ & $38(69.1 \%)$ & $0(0 \%)$ \\
\hline Mobility & $19.6 \pm 25.4$ & $24(43.6 \%)$ & $1(1.8 \%)$ \\
\hline Sleep & $20.3 \pm 28.8$ & $27(49.1 \%)$ & $1(1.8 \%)$ \\
\hline Emotional reaction & $26.1 \pm 34.8$ & $26(47.3 \%)$ & $3(5.5 \%)$ \\
\hline \multicolumn{4}{|l|}{ SF 36} \\
\hline Physical pain & $54.5 \pm 35$ & $13(23.6 \%)$ & $3(5.5 \%)$ \\
\hline Emotional well-being & $43.5 \pm 13.6$ & $0(0 \%)$ & $0(0 \%)$ \\
\hline General health & $55.6 \pm 20.9$ & $0(0 \%)$ & $0(0 \%)$ \\
\hline Physical functioning & $65.5 \pm 33.7$ & $10(18.2 \%)$ & $4(7.3 \%)$ \\
\hline Social functioning & $58.8 \pm 45.3$ & $10(18.2 \%)$ & $3(5.5 \%)$ \\
\hline Limitations due to emotional problems & $59.5 \pm 44.2$ & $28(50.9 \%)$ & $17(30.9 \%)$ \\
\hline Limitations due to physical health & $45.9 \pm 19.4$ & $26(47.3 \%)$ & $16(29.1 \%)$ \\
\hline Energy & $58.8 \pm 26.2$ & $0(0 \%)$ & $0(0 \%)$ \\
\hline Average physical score & $52.7 \pm 20.7$ & $0(0 \%)$ & $0(0 \%)$ \\
\hline Average emotional score & $54.5 \pm 35$ & $0(0 \%)$ & $0(0 \%)$ \\
\hline
\end{tabular}

Results expressed as mean and standard deviation. Number of patients with minimal and maximal scores is expressed in numeric values and percentages

An elevated percentage of maximal scores was observed in the "physical pain" (23.6\%), "physical functioning" (18.2\%) and "social functioning" (18.2\%) dimensions with the following average scores $54.5 \pm 35$, $65.5 \pm 33.7$ and $58.8 \pm 45.3(0 / 100$ corresponding to the worst score and 100/100 corresponding to the best score).

As an indication, we compared quality of life of the studied population to a reference group from an INSEE survey. Comparison is shown in Table 3. The calculation of statistical significance was not possible due to the difference in the number of patients between the groups and the comparison is given for information purposes only.

The results could suggest that there are alterations in all quality of life dimensions in patients who had suffered major trauma except for three: "energy", "average physical score" and "average mental score".

Table 3 Comparison between the trauma group and a reference group of mean (SD) SF-36 scores

\begin{tabular}{llcl}
\hline SF-36 items & $\begin{array}{l}\text { Trauma group } \\
\mathbf{N = 5 5}\end{array}$ & $\begin{array}{l}\text { Reference group* } \\
\mathbf{N = \mathbf { 2 0 } , \mathbf { 7 5 4 }}\end{array}$ & $\begin{array}{l}\text { Difference } \\
\text { between the reference } \\
\text { and trauma patients }\end{array}$ \\
\hline Physical pain & $54.5 \pm 35$ & $73 \pm 24.6$ & -18.5 \\
Emotional well-being & $43.5 \pm 13.6$ & $66.7 \pm 17.7$ & -23.2 \\
General health & $55.6 \pm 20.9$ & $67.8 \pm 18.9$ & -12.2 \\
Physical functioning & $65.5 \pm 33.7$ & $85.3 \pm 22.3$ & -19.8 \\
Social functioning & $58.8 \pm 45.3$ & $80.9 \pm 21.2$ & -22.1 \\
Limitations due to emotional problems & $59.5 \pm 44.2$ & $82 \pm 32.9$ & -22.5 \\
Limitations due to physical health & $45.9 \pm 19.4$ & $82.2 \pm 32.2$ & -36.3 \\
Energy & $58.8 \pm 26.2$ & $57.4 \pm 18$ & 1.4 \\
Average physical score & $52.7 \pm 20.7$ & $50.3 \pm 9.1$ & 2.4 \\
Average mental score & $54.5 \pm 35$ & $47.2 \pm 9.7$ & 7.3 \\
\hline
\end{tabular}

Results are expressed in averages and standard deviations for data from the INSEE study* and in numerical values with regards to the variation in averages in quality of life in both populations. The calculation of statistical significance is not possible due to the difference in the number of patients between the groups and the comparison is given for information purposes only 
Physical dimensions could be the ones most affected by moderate to severe trauma.

Psychological dimensions, notably "emotional wellbeing" (-23.2), "social functioning" $(-22.1)$ and "limitations due to emotional problems" $(-22.5)$ reveal lower scores than those of the general population.

This comparative analysis suggests that both the physical and psychological impact of moderate to severe trauma.

\section{Factors associated with disability}

This study revealed an absence of statistically significant correlations between injury, location of initial injury and quality of life scores.
A comparative analysis was done on the clinical data and the quality of life scores for patients with a disability status and those who were considered able-bodied (Table 4).

According to the statistical data, disabled patients required longer rehabilitation and needed personal assistance more often.

The NHP score corroborated results obtained with the MOS SF-36 score since the "pain" and "mobility" dimensions statistically decreased in the disabled group. Results also indicated significant decreases in the "energy" and "emotional reactions" dimensions.

Therefore, the results highlight significant discrepancies between the able-bodied population and the

Table 4 Comparison of the clinical data and quality of life scores of the able-bodied population and the population with a disability

\begin{tabular}{|c|c|c|c|}
\hline & $\begin{array}{l}\text { Able-bodied }(n=35) \\
\text { Median }(25-75 P)\end{array}$ & $\begin{array}{l}\text { Disabled }(n=20) \\
\text { Median }(25-75 P)\end{array}$ & $p$ \\
\hline \multicolumn{4}{|l|}{ Clinical data and length of stay } \\
\hline Age at occurrence of trauma (years) & $48(28.5-59)$ & $44.5(36-52)$ & 0.75 \\
\hline Men/Women n (\%) & $30(85.7 \%) / 5(14.3 \%)$ & $13(65 \%) / 7(35 \%)$ & 0.09 \\
\hline SAPS $\|$ & $25(18-37)$ & $29(19-40.5)$ & 0.37 \\
\hline ISS & $18(13-25)$ & $22(13-26)$ & 0.40 \\
\hline Emergency surgery & $51.4 \%$ & $55 \%$ & 0.99 \\
\hline \multicolumn{4}{|l|}{ Length of time (days) } \\
\hline $\mathrm{ICU}$ & $11(5-22.5)$ & $14(9.5-27.5)$ & 0.28 \\
\hline Mechanical ventilation & $0(0-10)$ & $4(0-15)$ & 0.29 \\
\hline In the hospital & $20(10.2-40.5)$ & $28.5(21.5-36.5)$ & 0.09 \\
\hline Rehabilitation (months) & $3(2.25-6.5)$ & $8(4.75-29.2)$ & $0.0113^{*}$ \\
\hline Resumption of professional activity & $58.8 \%$ & $42.1 \%$ & 0.27 \\
\hline Employment of a caregiver & $7(20 \%)$ & $11(55 \%)$ & $0.015^{*}$ \\
\hline \multicolumn{4}{|l|}{ MOS SF-36 } \\
\hline Physical pain & $70.5(28.1-100)$ & $25(12.5-56)$ & $0.0029^{*}$ \\
\hline Emotional well-being & $45(31.25-55)$ & $42.5(35-52.5)$ & 0.94 \\
\hline General health & $53(44.7-75.7)$ & $48.9(39-71.7)$ & 0.37 \\
\hline Physical functioning & $90(55-100)$ & $50(27.5-72.5)$ & $0.0008^{*}$ \\
\hline Social functioning & $87.5(44.6-100)$ & $41.5(29-70.5)$ & $0.0011^{*}$ \\
\hline Limitations due to emotional problems & $100(8.3-100)$ & $33.3(0-100)$ & 0.05 \\
\hline Limitations due to physical health & $100(31.3-100)$ & $25(0-87.5)$ & $0.0095^{*}$ \\
\hline Energy & $43.7(32.8-60.9)$ & $43.75(25-53.1)$ & 0.29 \\
\hline Average physical score & $73.7(53-85.6)$ & $43(25-61.1)$ & $0.0015^{*}$ \\
\hline Average emotional score & $65.6(42-72.9)$ & $44.3(25-60.7)$ & $0.0124^{*}$ \\
\hline \multicolumn{4}{|l|}{ NHP } \\
\hline Pain & $0(0-27.8)$ & $45.9(10.4-86.4)$ & $0.0037^{*}$ \\
\hline Energy & $0(0-39)$ & $100(30.5-100)$ & $<0.0001^{*}$ \\
\hline Social isolation & $0(0-12.3)$ & $0(0-59.3)$ & 0.16 \\
\hline Mobility & $0(0-11.5)$ & $32,6(11.5-52.7)$ & $0.0001^{*}$ \\
\hline Sleep & $0(0-16.5)$ & $13.95(0-47.5)$ & 0.42 \\
\hline Emotional reactions & $0(0-34.7)$ & $35.4(4.4-45.9)$ & $0.0201^{*}$ \\
\hline
\end{tabular}


disabled population when comparisons were made between the MOS SF-36 scale and the NHP scale. Some dimensions (physical and emotional) were statistically lower in the disabled group. Therefore, we can hypothesize that these dimensions are predictive factors of disability and quality of life impairment after moderate to severe trauma.

Concerning the MOS SF-36 score, disabled patients had significant decreases for all physical dimensions ("pain", "physical functioning", "limitations due to physical health" and "average physical score") compared to the group of able-bodied patients. Nevertheless, it was noted that the MOS SF-36 scale demonstrated a statistically significant difference between two items of the emotional dimension: "social functioning" and "average emotional score".

A univariate analysis was done by completing ROC curves (Fig. 2) for every statistically different dimension of the MOS SF-36 and NHP scale in the disabled group.

The dimensions for "physical functioning" with a threshold $\leq 85$ and "social functioning" with a threshold $\leq 75$ items of the MOS SF-36 scores as well as the dimensions for "mobility" with a threshold $>8.5$ and "energy" with a threshold $>61$ of the NHP score were the most associated with disability (Table 5).

According to the multivariate analysis (Table 6), the physical functioning item with a threshold less than or equal to 85 was statistically predictive of disability. It was noted that the statistical model presented has an AUC
(Area under the curve) of 0.87 which allows classification of $81.5 \%$ of the patients in the correct category.

In the MOS SF-36 scale, physical functioning score lower than or equal to 85 were a predictive factor of disability and consequently a factor of altered quality of life.

\section{Discussion}

The analysis of quality of life more than five years after moderate to severe trauma showed significant quality of life impairment with a predominant impact on physical dimensions.

Most of the sample patients were male and young which corresponds with prior studies [11, 12, 14-17].

The first meaningful result of our study was the impact of trauma on daily life. As a matter of fact, almost $17 \%$ of the patients had not resumed their professional activity, while more than $20 \%$ of the patients needed professional re-training and more than $16 \%$ had to have their work place adapted to accommodate their disability. As for patients who had resumed their professional activity, only $68 \%$ were able to undertake this on a full-time basis. These results correspond with findings in prior studies.

In fact, in 1998 and 2005, Braithwaite et al. [11] and Sluys et al. [12] gathered data that demonstrated a resumption of activity in $74 \%$ and $68 \%$ of the cases respectively for severely injured patients approximately 5 years following their injury. More recently, in a study conducted in 2016 on 147 patients with multiple traumas with medical follow-up of up to five years after the initial
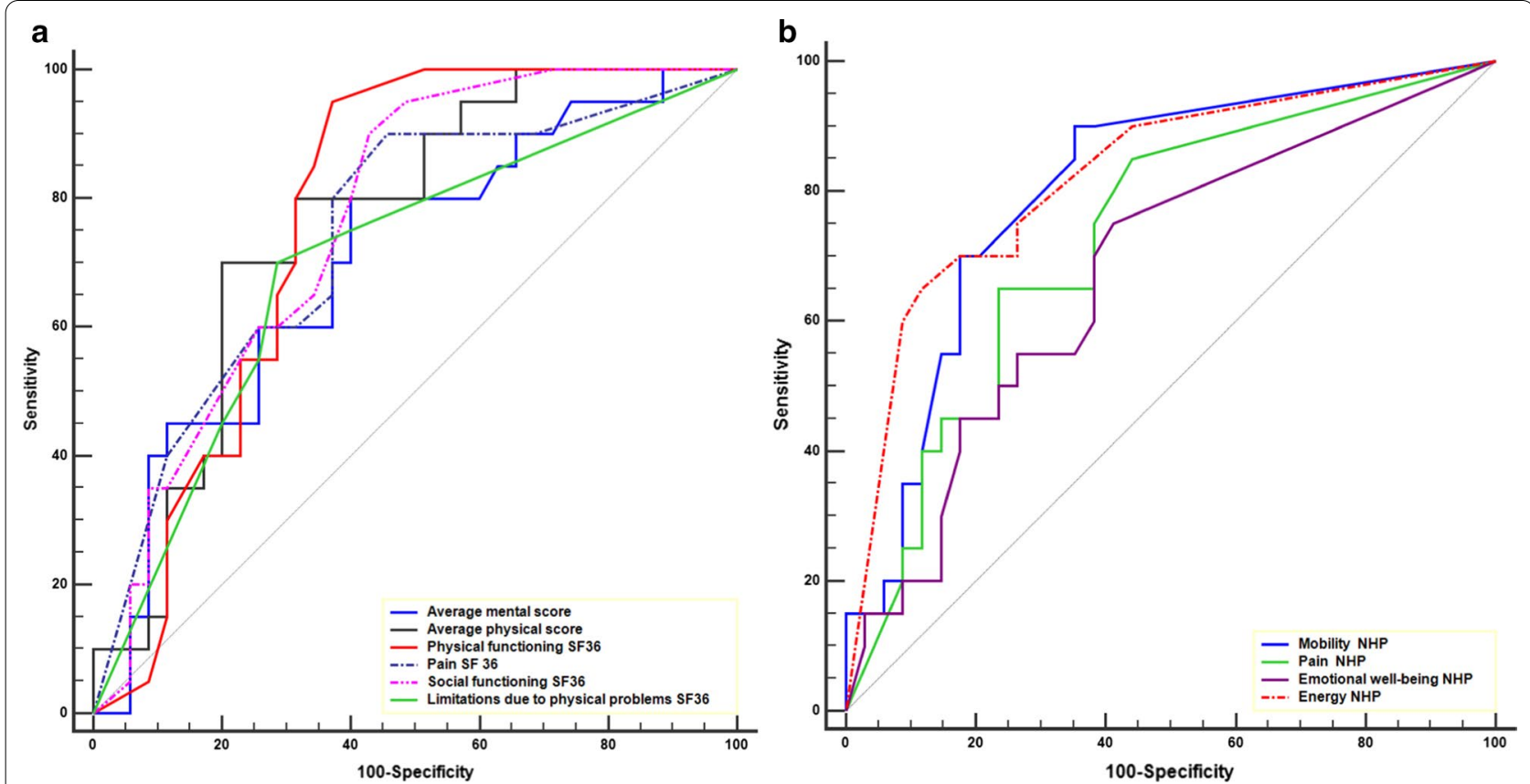

Fig. 2 Comparison of ROC curves of statistically significant MOS SF-36 (a) and NHP (b) scores 
Table 5 Areas under the ROC curve for dimensions associated with disability

\begin{tabular}{|c|c|c|c|c|c|c|c|c|}
\hline & AUC & $95 \% \mathrm{Cl}$ & $\mathrm{p}$ & Threshold & Se & Sp & PPV & PNV \\
\hline \multicolumn{9}{|l|}{ SF36 } \\
\hline Physical pain & 0.74 & $0.61-0.85$ & $0.0005^{*}$ & $\leq 66.5$ & 90 & 54.29 & 52.9 & 90.5 \\
\hline Physical functioning & 0.77 & $0.64-0.88$ & $<0.0001^{*}$ & $\leq 85$ & 95 & 62.86 & 59.4 & 95.7 \\
\hline Social functioning & 0.77 & $0.63-0.87$ & $<0.0001^{*}$ & $\leq 75$ & 90 & 57.1 & 54.5 & 90.9 \\
\hline $\begin{array}{l}\text { Role limitations due to physical } \\
\text { problems }\end{array}$ & 0.70 & $0.56-0.82$ & $0.0050^{*}$ & $\leq 50$ & 70 & 71.4 & 58.3 & 80.6 \\
\hline Average physical score & 0.76 & $0.63-0.87$ & $0.0001^{*}$ & $\leq 47.3$ & 70 & 80 & 66.7 & 82.4 \\
\hline Average emotional score & 0.7 & $0.57-0.82$ & $0.0057^{*}$ & $\leq 62.2$ & 80 & 60 & 53.3 & 84 \\
\hline \multicolumn{9}{|l|}{ NHP } \\
\hline Mobility & 0.81 & $0.68-0.9$ & $<0.0001^{*}$ & $>8.51$ & 90 & 65.7 & 60 & 92 \\
\hline Pain & 0.73 & $0.59-0.84$ & $0.0009^{*}$ & $>29.54$ & 65 & 77.1 & 61.9 & 79.4 \\
\hline Energy & 0.82 & $0.69-0.91$ & $<0.0001^{*}$ & $>61.02$ & 65 & 88.2 & 76.5 & 81.1 \\
\hline Emotional reactions & 0.68 & $0.54-0.80$ & $0.0131^{*}$ & $>0$ & 75 & 60 & 51.7 & 80.8 \\
\hline
\end{tabular}

AUC, 95\% Cl and threshold values expressed in numerical values. Se, Sp, VPP and VPN expressed in percentages. ${ }^{*} p<0.05$. Se, sensibility; Sp, specificity; PPV, positive predictive value and NPV, negative predictive value

Table 6 Multivariate analysis of predictive factors of disability based on the quality of life scores

\begin{tabular}{lcll}
\hline & OR & $\mathbf{9 5 \% ~ C l}$ & $\boldsymbol{p}$ value \\
\hline Average physical score $\leq 47.3$ & 1.7 & $0.26-11.13$ & 0.5799 \\
Energy NHP $>61.02$ & 5.9 & $0.85-40.9$ & 0.0733 \\
Pain NHP $>29.54$ & 0.43 & $0.05-3.73$ & 0.4419 \\
Physical functioning SF36 $\leq 85$ & 16.5 & $1.43-191.32$ & $0.0247^{*}$
\end{tabular}

NHP: Nottingham Health Program, SF36: Short Form-36, 95\% Confidence Interval, ${ }^{*} p<0.05$

AUC of the statistical model $=0.87$ which allows classification of $81.5 \%$ of the patients in the correct category

trauma, Zwingmann et al. [17] found a loss of professional activity in $16 \%$ of the cases.

Furthermore, a disability status was acknowledged in $36.4 \%$ of the patients in the study cohort. Note that this status is assigned to patients with a decreased capacity to work and with earnings reduced by at least two thirds, or due to their health status after an accident or a non-occupational related illness. This status provides grounds for a disability allowance, and the allotted amount depends on the category of disability in which patients are classified. These results highlight the serious impact of trauma. The capacity to work was altered in a majority of the population studied, and this alteration in professional life generated a significant loss of income for patients, and represents a major economic and human cost for the society.

In addition, we assessed the quality of life of patients by combining two standardized scales: the MOS SF-36 and the NHP scales. These two scales were combined in order to include patients with brain or head injury. As a matter of fact, in the Gross et al. [15] study, the authors concluded that this association enabled them to carry out the most accurate assessment of quality of life in a population of multiple trauma patients presenting with a potential traumatic brain injury. Van Beeck and coll. propose to use a combination of EuroQol-5D and Health Utilities Mark Ill in all studies on injury-related disability [18]. Ardolino A and coll in a consensus meeting also suggest the use of European Quality of Life 5D (EQ-5D) with consideration to be given to the World Health Organisation Quality of Life survey (WHO-QoL) [19].

The MOS SF-36 and NHP scales provided an objective basis to arrive at the conclusion of significant quality of life impairment in the population studied. The somatic element appeared to be more affected than the emotional element, notably according to the NHP scale. In a study conducted in 2004, Dimopoulou et al. also found data indicating significant physical health impairment according to the NHP scale in a population of multiple trauma patients with medical follow-up of up to a year after the initial trauma (64\% of the patients presented with impairment in health dimensions such as "mobility", "energy" and "pain") [16].

In the BRAIN ICU study [4], the authors demonstrated that approximately one third of the patients hospitalized in the ICU, regardless of their injury, presented with mild depression at 3 and 12 months after trauma, and that the somatic dimension was the primary factor underlining mood fluctuations. Finally, in the Gross study, $76 \%$ of the multiple trauma patients presented with chronic pain, two years after their injury [15].

When the results of the MOS SF-36 were compared with those found in the French reference population of 
the decennial study conducted by INSEE in 2002-2003, deterioration in quality of life also prevailed in the dimensions of the somatic components. These results seem to correspond with those obtained in the Sluys et al. study [12]. In fact, the authors identified lowered scores in all aspects of health studied, and also reported that $68 \%$ of the patients suffered from a physical disability, whereas only $41 \%$ of the patients presented with emotional impairments.

Therefore, these results highlight the fact that major trauma affects not only the somatic dimension, but the emotional dimension as well. Nevertheless, physical impairments seem to be the main source of disability perceived by patients.

Based on these findings, it could be beneficial to propose early emotional and physical rehabilitation for this population in order to decrease the impact on quality of life following hospitalization. Van der Schaaf et al. have shown that patients who received care in the ICU for at least two days are the target population for the introduction of rehabilitation programs; which include not only physical exercise aimed at improving walking and endurance, but also care for emotional distress and problems related to concentration and memory [20]. In a study published in 2012, Jackson et al. underscored the importance of rehabilitation programs dedicated to patients who had received care in the ICU. With physical, cognitive and functional training, patients' future improved in only 3 months [21].

Finally, we specifically analyzed the subgroup of disabled patients. Our study showed that physical functioning scores with a threshold $\leq 85$ on the MOS SF-36 scale were predictive of disability according to criteria established by the French Health Insurance Agency. To our knowledge, there are no studies that have specifically identified a predictive factor for disability based on quality of life assessment scales. However, these results have yet to be validated by the completion of multi-centric prospective studies.

There are several limitations in our study. First of all, it is a monocentric analysis. However, the study population seems similar to other studies conducted on cohorts of multiple trauma patients, (in terms of age, gender, length of hospitalization and the severity of the initial injury) $[11,12,14,16,17]$. Second, the participation rate in this study was lower than in other studies conducted on the outcomes for victims of severe injuries. However, a comparative analysis was done of patients who did not participate and those who did and the results indicated an absence of statistically significant discrepancies between the two populations. This indicates the representativeness of our cohort with respect to the total population contacted for the study. Finally, the history of somatic or psychiatric disorders in the population studied was not explored, which could have had an impact on the scores obtained from the quality of life assessment.

\section{Conclusion}

Our study shows that more than 5 years after a moderate to severe trauma, there is a significant alteration in the quality of life. Disability secondary to major trauma is predicted by the presence of a physical functioning score $\leq 85$ on the MOS SF-36 scale. This finding should be grounds for the introduction of specific rehabilitation programs (including physical and emotional components), implemented in intensive care units in order to limit the long-term consequences of major trauma on patients, and the resulting socio-economic impacts. There are differences in the long-term quality of life of trauma patients compared to the quality of life of the general French population, with the limitation that these outcomes have to been adjusted for the different age/ sex categorization in the study sample versus the general population sample.

\section{Abbreviations}

ARDS: Acute Respiratory Distress Syndrome; AUC: Area under the curve; ICU: Intensive Care Unit; INSEE: French Statistics and Economic Studies Institute; ISS: Injury Severity Score; MOS SF-36: Medical Outcome Study Short Form-36; NHP: Nottingham Health Profile; PICS: Post-Intensive Care Syndrome; ROC: Receiver Operating Characteristics; SAPS II: New Simplified Acute Physiology Score ll.

\section{Acknowledgements \\ Not applicable.}

Authors' contributions

$F V-B, R G, T A, L C, T A$, and FL designed the study and contacted the patients. $F V-B, R G, B G$ and JMC analyzed and interpreted the patient data. FV-B and RG wrote the manuscript. TG, BG, JMC, and VM corrected the manuscript. All the authors read and approved the final manuscript.

\section{Funding}

Not applicable.

\section{Availability of data and materials}

The datasets used and/or analyzed in this study are available from the corresponding author on reasonable request.

\section{Ethics approval and consent to participate}

The Toulouse University Hospital ethics and research committee approved this study (project number 08-0916). Informed consent was obtained through forms from all the participants of the study.

\section{Consent for publication}

Not applicable.

\section{Competing interests}

The authors declare that they have no competing interests.

\section{Author details}

${ }^{1}$ Anesthesiology and Critical Care Unit, Toulouse University Hospital, 1 av du Pr Jean Poulhès, 31059 Toulouse, France. ${ }^{2}$ Inserm U1048, I2MC, Université Paul Sabatier, 31024 Toulouse Cedex 03, France. 
Received: 29 November 2019 Accepted: 16 December 2020

Published online: 08 January 2021

\section{References}

1. Garric J. Epidemiology of multiple trauma. Soins. 2013;778:26-8.

2. Bège T, Pauly V, Orleans V, Boyer L, Leone M. Epidemiology of trauma in France: mortality and risk factors based on a national medico-administrative database. Anaesth Crit Care Pain Med. 2019;38:461-8.

3. Elliott DC, Rodriguez A. Cost effectiveness in trauma care. Surg Clin North Am. 1996;76(1):47-62

4. Jackson JC, Pandharipande PP, Girard TD, Brummel NE, Thompson $J \mathrm{~L}$, Hughes CG, et al. Depression, post-traumatic stress disorder, and functional disability in survivors of critical illness in the BRAIN-ICU study: a longitudinal cohort study. Lancet Respir Med. 2014;2(5):369-79.

5. Bienvenu OJ, Colantuoni E, Mendez-Tellez PA, Dinglas VD, Shanholtz C, Husain N, et al. Depressive symptoms and impaired physical function after acute lung injury: a 2-year longitudinal study. Am J Respir Crit Care Med. 2012:185(5):517-24.

6. Herridge MS, Tansey CM, Matté A, Tomlinson G, Diaz-Granados N, Cooper $A$, et al. Functional disability 5 years after acute respiratory distress syndrome. N Engl J Med. 2011;364(14):1293-304.

7. Iwashyna TJ, Ely EW, Smith DM, Langa KM. Long-term cognitive impairment and functional disability among survivors of severe sepsis. JAMA. 2010;304(16):1787.

8. Pandharipande PP, Girard TD, Jackson JC, Morandi A, Thompson JL, Pun BT, et al. Long-term cognitive impairment after critical illness. N Engl 」 Med. 2013;369(14):1306-16.

9. Wolters AE, Slooter AJC, van der Kooi AW, van Dijk D. Cognitive impairment after intensive care unit admission: a systematic review. Intensive Care Med. 2013;39(3):376-86.

10. Von Rüden C, Woltmann A, Röse M, Wurm S, Rüger M, Hierholzer C, et al. Outcome after severe multiple trauma: a retrospective analysis. J Trauma Manag Outcomes. 2013:7(1):4

11. Braithwaite JJ, Boot DA, Patterson M, Robinson A. Disability after severe injury: five year follow up of a large cohort. Injury. 1998;29(1):55-9.
12. Sluys K, Haggmark T, Iselius L. Outcome and quality of life 5 years after major trauma. J Trauma Inj Infect Crit Care. 2005;59(1):223-32.

13. Bucquet $D$, Condon $S$, Ritchie $K$. The French version of the Nottingham Health Profile. A comparison of items weights with those of the source version. Soc Sci Med. 1990;30(7):829-35.

14. Pape H-C, Zelle B, Lohse R, Hildebrand F, Krettek C, Panzica M, et al. Evaluation and outcome of patients after polytrauma-Can patients be recruited for long-term follow-up? Injury. 2006;37(12):1197-203.

15. Gross T, SchüEpp M, Attenberger C, Pargger H, Amsler F. Outcome in polytraumatized patients with and without brain injury: quality of life following polytrauma. Acta Anaesthesiol Scand. 2012;56(9):1163-74.

16. Dimopoulou I, Anthi A, Mastora Z, Theodorakopoulou M, Konstandinidis $A$, Evangelou E, et al. Health-related quality of life and disability in survivors of multiple trauma one year after intensive care unit discharge. Am 」 Phys Med Rehabil. 2004;83(3):171-6.

17. Zwingmann J, Hagelschuer P, Langenmair E, Bode G, Herget G, Südkamp NP, et al. Lower health-related quality of life in polytrauma patients: long-term follow-up after over 5 years. Medicine (Baltimore). 2016;95(19):e3515.

18. Van Beeck EF, Larsen CF, Lyons RA, Meerding WJ, Mulder S, Essink-Bot ML. Guidelines for the conduction of follow-up studies measuring injuryrelated disability. J Trauma. 2007;62(2):534-50.

19. Ardolino A, Sleat $G$, Willett K. Outcome measurements in major traumaresults of a consensus meeting. Injury. 2012;43(10):1662-6.

20. Van der Schaaf M, Beelen A, Dongelmans D, Vroom M, Nollet F. Functional status after intensive care: A challenge for rehabilitation professionals to improve outcome. J Rehabil Med. 2009:41(5):360-6.

21. Jackson JC, Ely EW, Morey MC, Anderson VM, Denne LB, Clune J, et al. Cognitive and physical rehabilitation of intensive care unit survivors: results of the RETURN randomized controlled pilot investigation. Crit Care Med. 2012:40(4):1088-97.

\section{Publisher's Note}

Springer Nature remains neutral with regard to jurisdictional claims in published maps and institutional affiliations.
Ready to submit your research? Choose BMC and benefit from:

- fast, convenient online submission

- thorough peer review by experienced researchers in your field

- rapid publication on acceptance

- support for research data, including large and complex data types

- gold Open Access which fosters wider collaboration and increased citations

- maximum visibility for your research: over 100M website views per year

At BMC, research is always in progress.

Learn more biomedcentral.com/submissions 